\title{
Field Weakening Control of a Separately Excited DC Motor Using Neural Network Optemized by Social Spider Algorithm
}

\author{
Waleed I. Hameed', Ahmed S. Kadhim¹, Ali Abdullah K. Al-Thuwaynee² \\ ${ }^{1}$ Department of Communication Engineering, Iraqi University College, Basrah, Iraq \\ ${ }^{2}$ Department of Electrical Engineering, University of Basrah, Basrah, Iraq \\ Email: waleed_ishaq5@yahoo.com
}

Received 1 December 2015; accepted 16 January 2016; published 19 January 2016

Copyright (C) 2016 by authors and Scientific Research Publishing Inc.

This work is licensed under the Creative Commons Attribution International License (CC BY). http://creativecommons.org/licenses/by/4.0/

c) (i) Open Access

\begin{abstract}
This paper presents the speed control of a separately excited DC motor using Neural Network (NN) controller in field weakening region. In armature control, speed controller has been used in outer loop while current controller in inner loop is used. The function of NN is to predict the field current that realizes the field weakening to drive the motor over rated speed. The parameters of NN are optimized by the Social Spider Optimization (SSO) algorithm. The system has been implemented using MATLAB/SIMULINK software. The simulation results show that the proposed method gives a good performance and is feasible to be applied instead of others conventional combined control methods.
\end{abstract}

\section{Keywords}

DC Motor Drive, Field Weakening, Neural Network, Social Spider Optimization

\section{Introduction}

DC motors are used in many applications and industrial fields, because they can provide a high starting torque. It is also possible to obtain speed control over wide range below and above the rated speed [1]. It is well known that the speed of separately excited DC motor (SEDCM) can be achieved either by varying the armature voltage (armature control) or the field current (field control) [2]. The speed is directly proportional to the armature voltage and inversely proportional to the field current. In armature control, one can get constant reference speed up to rated over the whole load range [3]. However, in the field control, constant reference speed up to $120 \%-130 \%$ rated can be achieved but with loss of the motor developed torque. In this paper, neural network controller has 
been proposed to operate the DC motor in the field weakening region. This controller has been used to reduce the field current and then increase the speed of motor over rated speed. This paper is organized as follows: a mathematical model of SEDC motor operating in both armature and field weakening regions is given in Section 2; combined control of SEDCM with proposed method has been presented in Section 3; a brief description of neural networks is given in Section 4; in Section 5, a Social Spider Optimization (SSO) algorithm has been developed. Simulation results are given in Section 6, and finally, conclusions are given in Section 7.

\section{Modeling of SEDCM}

The quivalent circuit of a separately exited DC-Motor is shown in Figure 1 below. Dependent on the quivalent circuit, the mathmetical equations of the motor are obtained using electromechanical energy conversion and torque balance rules as follows [2] [3]:

$$
\begin{gathered}
v_{a}=R_{a} i_{a}+L_{a}\left(\frac{\mathrm{d} i_{a}}{\mathrm{~d} t}\right)+e_{a} \\
e_{a}=K_{m} \omega_{m} \\
K_{m}=L_{a f} i_{f} \\
T_{e}=K_{m} i_{a} \\
J\left(\frac{\mathrm{d} \omega_{m}}{\mathrm{~d} t}\right)=T_{e}-T_{L}-B_{m} \omega_{m} \\
v_{f}=R_{f} i_{f}+L_{f}\left(\frac{\mathrm{d} i_{f}}{\mathrm{~d} t}\right)
\end{gathered}
$$

where $v_{a}$ and $v_{f}$ are the applied terminal voltage to the motor and field voltage, $e_{a}$ is the emf induced in the armature winding, The resistances $R_{a}$ and $R_{f}$ are the armature and field resistances, $L_{a}$ and $L_{f}$ are the armature and field inductances, $i_{a}$ and $i_{f}$ are the armature motor current and field current, $L_{a f}$ mutual inductance, $K_{m}$ is the motor constant, $\omega_{m}$ is the motor speed, $T_{e}$ is the internal torque of the motor, $J$ is the rotational inertia of motor, $B_{m}$ is the viscous friction of motor and $T_{L}$ the load torque.

\section{Combined Control of SEDCM}

The main advantage of DC motors is simple in the speed control. As the motor angular speed $\omega_{m}$, is directly proportional to armature voltage and inversely proportional to the magnetic flux produced by the field current, adjusting the armature voltage and/or the field current will change the rotor angular speed [4]. The separately excited DC motor (SEDM) is usually supplied by two controlled voltage sources, that can be controlled rectifiers or choppers. One source is supplying the motor armature winding with the armature voltage, $v_{a}$, and the other is supplying the motor field winding by the field voltage $v_{f}$. The speed of the SEDM can be controlled by controlling either the armature voltage $v_{a}$ or the field voltage $v_{f}$, or both of them. Usually, the voltage speed

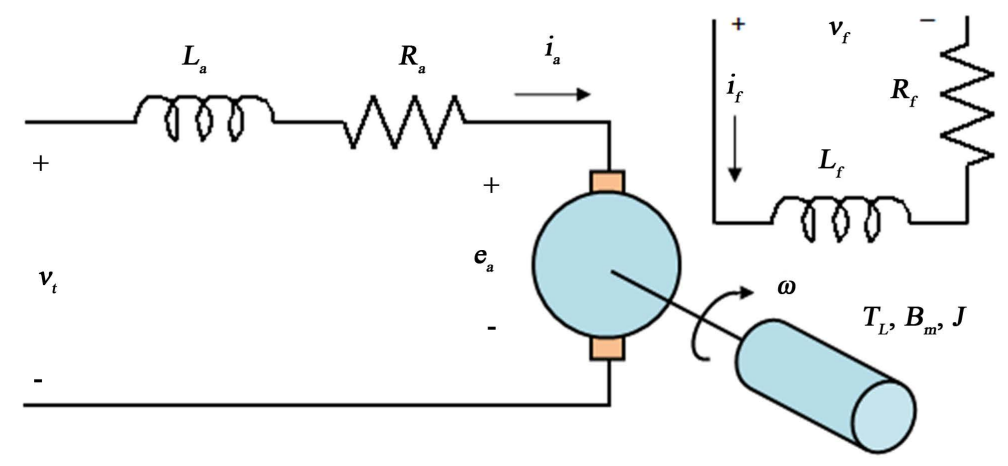

Figure 1. The quivalent circuit of a separately exited DC-motor. 
control method is used to control the speed of the SEDM below its rated speed. In this method, the field voltage $v_{f}$ is kept constant, while the armature voltage $v_{a}$ is varied. A constant field voltage $v_{f}$ produces a constant field current $I_{f}$, which in turn, produces a constant magnetic flux in the motor air-gap. Hence, the torque produced on the motor shaft remains constant, as the armature current remains constant.

The motor angular speed $\omega_{m}$ and the power on the motor shaft are linearly proportional to the armature voltage $v_{a}$. To run the SEDM above its rated speed, the field weakening method is used. Here, the field current $I_{f}$ is reduced by reducing the field voltage $v_{f}$. The magnetic flux in the motor air gap will be reduced, causing reduction of the back emf $e_{a}$. The motor armature current will increase, resulting in increasing the motor speed. As a result of that, the back emf $e_{a}$ will increase and a new equilibrium will be established at a higher speed. In other words, with decreasing the field voltage $v_{f}$, the motor angular speed $\omega_{m}$ increases, while the motor torque decreases and the motor shaft power remains constant [5]. The block diagram of conventional combined control is shown in Figure 2 below.

In this paper we propose a new method to increase the speed of the motor above the rated value ( $N$ rated). The new method based on predict the duty ratio $(D)$ that give the field voltage $v_{f}$ and thus give the require current field $i_{f}$. This can be realized by using the ability of neural networks (NNs) in prediction and control. Assume that this method don't need to sensors for current field $i_{f}$ and armature voltage $e_{a}$. Also in this method, the predicted field current will keep the armature voltage of the motor under the rated value. Figure 3 below show the block diagram of the proposed method.

\section{Neural Network}

The structure of an artificial neuron is inspired by the concept of a biological neuron. Neural Network (NN) basically performs input output mapping which can be static or dynamic. One important feature of NN is that it normally requires supervised training (or learning) by input-output example data sets unlike conventional programming of digital computer [6]. In learning process, neural network adjusts its structure such that it is able to output the same signals as the supervisor. The learning is repeated until the difference between network output and supervisor is enough [7]. The basic model of a single artificial neuron consists of a weighted summer and an activation (or transfer) function as shown in Figure 4.

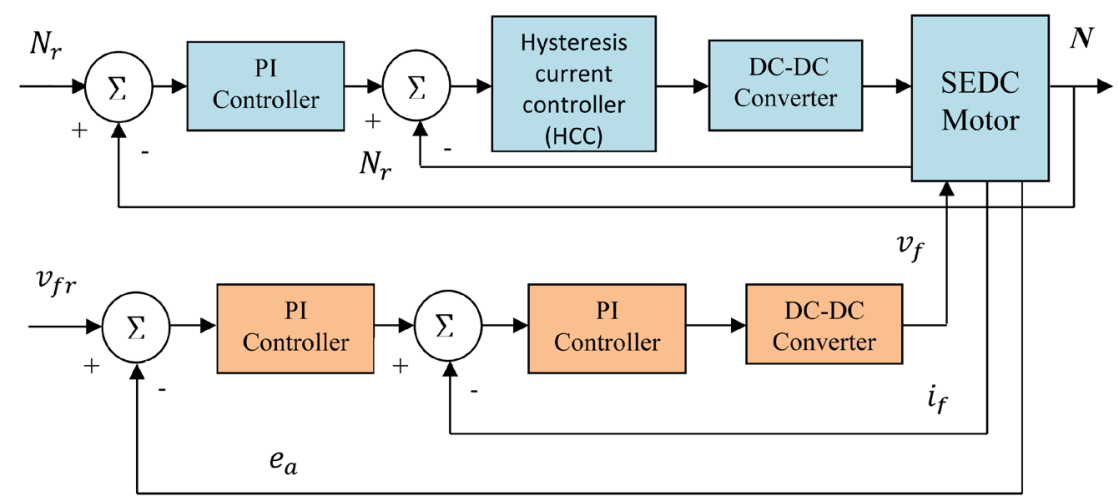

Figure 2. Block diagram of conventional combined control for SEDCM.

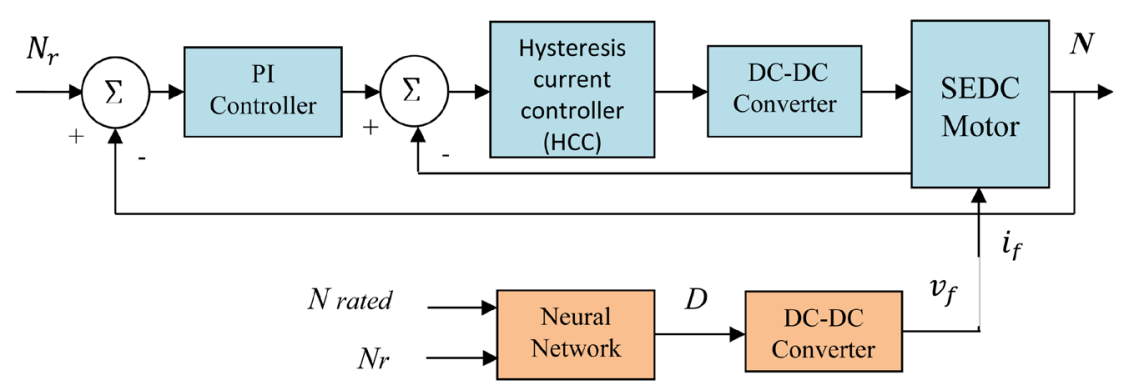

Figure 3. Block diagram of proposed field weakening control. 


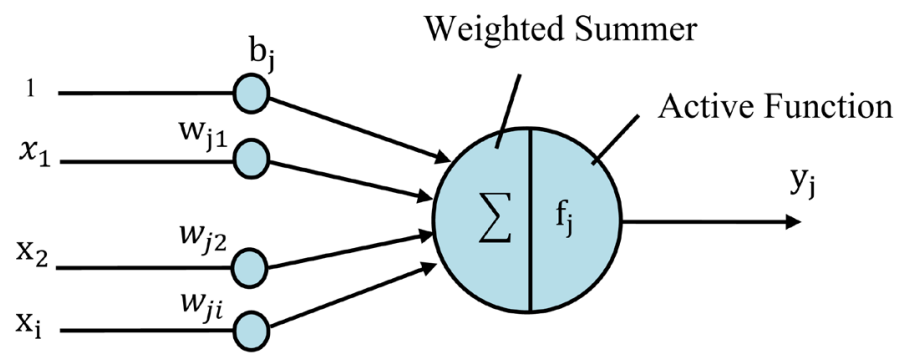

Figure 4. Basic model of a single artificial neuron.

where:

$x_{1}, \cdots, x_{i}$ are inputs;

$w_{j 1}, \cdots, w_{j i}$ are weights;

$b_{j}$ is bias;

$f_{j}$ is the activation function;

$y_{j}$ is the output.

The weights sum $s_{j}$ is therefore

$$
s_{j}=\sum_{i=1}^{N} w_{j i} x_{i}(t)+b_{j} .
$$

The sigmoid activation function is popular for neural network application. The equation for a sigmoid function is:

$$
f(s)=\frac{1}{1+\mathrm{e}^{-s_{j}}} .
$$

Feed forward network is a network of single neurons jointed together by synaptic connections. Figure 5 show a three-layer feed forward neural network [8].

\section{The Social Spider Optimization (SSO) Algorithm}

A new type of evolutionary technique, which is called Swarm intelligence has enticed much research interest [9]. The swarm expression is employed in a general manner to refer to any collection of interactive agents. Swarm intelligence is concerned with the methodology to model the attitude of social animals and insects for problem solving. Researchers invented optimization algorithms by simulating the behavior of ants, bees, bacteria, fireflies and other organisms [10]. Self-organization and job division are the basic components of swarm intelligence. Self-organizing system means; each of the covered units responds to local exciter individually and may act together to achieve a global mission, via a job separation which averts a localized supervision. This will efficiently adapt the entire system to internal and external changes [11]. A swarm algorithms are built up on several methods. Such methods involve the social behavior of bird herding such as the Particle Swarm Optimization (PSO) algorithm [12], the cooperative demeanor of bee colonies such as the Artificial Bee Colony (ABC) technique [13], the intermarriage demeanor of firefly insects such as the Firefly (FF) method [14] and imitation the cuckoo birds lifestyle such as the Cuckoo Optimization Algorithm (COA) [15].

The SSO supposes that entire search space is a sectarian web, where all the social-spiders react to each other. Each solution within the search space symbolizes a spider position in the communal web. Every spider receives a weight relating to the fitness value of the solution that is denoted by the social-spider. The algorithm supposes two different search agents (spiders): males and females. Depending on gender, each person is behaved by a set of different evolutionary operators which mimic different mutual behaviors that are commonly assumed within the colony. The computational steps for the SSO algorithm can be abstracted as follows [11]:

1) Considering $N$ as the total number of $n$-dimensional colony members, define the number of male $\mathrm{Nm}$ and females $N_{f}$ spiders in the entire population $S$.

$$
N_{f}=\text { floor }[(0.9-\operatorname{rand} \cdot 0.25) \cdot N] \text { and } N_{m}=N-N_{f}
$$




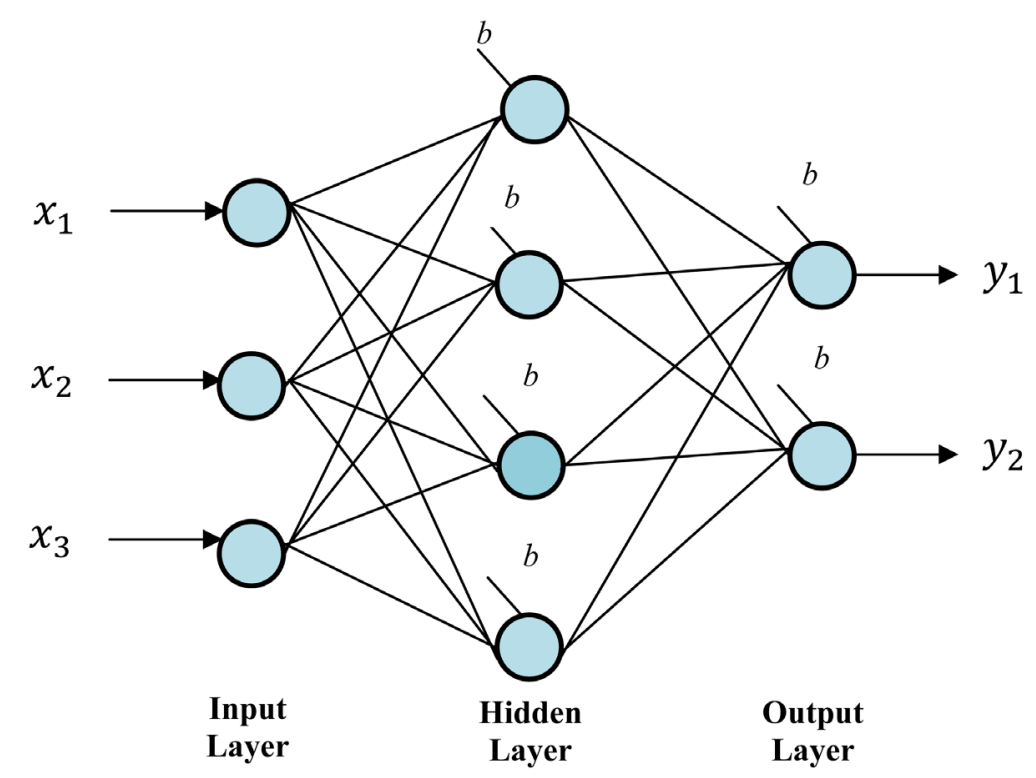

Figure 5. Three-layer feed forward neural network.

2) Initialize randomly the female $\left(F=\left\{f_{1}, f_{2}, \cdots, f_{N_{f}}\right\}\right)$ and male $\left(M=\left\{m_{1}, m_{2}, \cdots, m_{N_{m}}\right\}\right)$ members where $\left(S=\left\{s_{1}=f_{1}, s_{2}=f_{2}, \cdots, s_{N_{f}}=f_{N_{f}}, s_{N_{f}+1}=m_{1}, s_{N_{f}+2}=m_{2}, \cdots, s_{N}=m_{N_{m}}\right\}\right)$

$$
\begin{aligned}
& f_{i, j}^{0}=p_{j}^{\text {low }}+\operatorname{rand} \cdot\left(p_{j}^{\text {high }}-p_{j}^{\text {low }}\right) \\
& m_{k, j}^{0}=p_{j}^{\text {low }}+\text { rand } \cdot\left(p_{j}^{\text {high }}-p_{j}^{\text {low }}\right)
\end{aligned}
$$

and calculate the fitness of each individual.

3) Calculate the weight of every spider of $S$ as follows:

$$
w_{i}=\frac{J\left(s_{i}\right)-\text { worst }_{s}}{\text { best }_{s}-\text { worst }_{s}}
$$

where $J\left(s_{i}\right)$ is the fitness value obtained by the evaluation of the spider position $s_{i}$, best $s_{s}=\max _{k \in\{1,2, \cdots, N\}} J\left(s_{k}\right)$ and worst $_{s}=\min _{k \in\{1,2, \cdots, N\}} J\left(s_{k}\right)$.

4) Move female spider according to the female cooperative operator

The sectarian web is used as technique to transmit information among the colony individuals, this information is encoded as small vibrations. Each vibration depends on the weight and distance of the spider which has generated it.

There are two type of vibration:

a) $V i b c_{i}$ which is understood by the member $i$ as response of the information transmitted by the individual $c\left(s_{c}\right)$, where $c$ meant the nearest member to $i$ and assigns higher weight in comparison to $i$

$$
V i b c_{i}=w_{c} \cdot \mathrm{e}^{-d_{i, c}^{2}}
$$

where $d_{i, c}=\left\|s_{i}-s_{c}\right\|$.

b) $V i b b_{i}$ which is understood by the member $i$ as response of the information transmitted by the individual $b\left(s_{b}\right)$, where $b$ meant the best fitness value such that $w_{b}=\max _{k \in\{1,2, \cdots, N\}} w_{k}$

$$
V i b b_{i}=w_{b} \cdot \mathrm{e}^{-d_{i, b}^{2}}
$$


where $d_{i, b}=\left\|s_{i}-s_{b}\right\|$.

The movement of the female is depended on the attraction and repulsion, and they are depended on a uniform random number $r_{m}$ within range [0,1]. If $r_{m}$ is smaller than a threshold $P F$ an attraction is produced, otherwise a repulsion is generated.

The new position $f_{i}^{k+1}$ of the female $f_{i}^{k}$ is calculated as follows:

$$
f_{i}^{k+1}=\left\{\begin{array}{l}
f_{i}^{k}+\alpha \operatorname{Vibc_{i}}\left(s_{c}-f_{i}^{k}\right)+\beta V i b b_{i}\left(s_{b}-f_{i}^{k}\right)+\delta\left(\operatorname{rand}-\frac{1}{2}\right) \text { with probability } P F \\
f_{i}^{k}+\alpha \operatorname{Vibc_{i}}\left(s_{c}-f_{i}^{k}\right)+\beta V i b b_{i}\left(s_{b}-f_{i}^{k}\right)-\delta\left(\operatorname{rand}-\frac{1}{2}\right) \text { with probability } 1-P F
\end{array}\right.
$$

where $\alpha, \beta, \delta$ and rand are random value between [0,1], while $k$ represents the iteration number.

$5)$ move the male according to the cooperative operator

We have now the third type of vibration $V i b c_{i}$ (a vibration understood by the member $i$ as a result of the information transmitted by the member $f\left(s_{b}\right)$ where $f$ is the nearest female to individual $i$.

$$
\operatorname{Vibf} f_{i}=w_{f} \cdot \mathrm{e}^{-d_{i, f}^{2}}
$$

The male individuals are arranged in decreasing order according to their weight value, the individual whose weight $w_{N_{f}+m}$ is located in the middle is considered the median male individual. The change of positions will be as follows:

$$
m_{i}^{k+1}= \begin{cases}m_{i}^{k}+\alpha \operatorname{Vibf} f_{i}\left(s_{f}-m_{i}^{k}\right)+\delta\left(\text { rand }-\frac{1}{2}\right) & \text { if } w_{N_{f}+i}>w_{N_{f}+m} \\ m_{i}^{k}+\alpha\left(\frac{\sum_{h=1}^{N_{m}} m_{h}^{k} w_{N_{f}+h}}{\sum_{h=1}^{N_{m}} w_{N_{f}+h}}-m_{i}^{k}\right) & \text { if } w_{N_{f}+i}>w_{N_{f}+m}\end{cases}
$$

where $s_{f}$ represents the nearest female to the male $i$.

6) mating is performed by predominant males and females members, when a dominant male $m$ locates at a set of females within a specific range $r$, it mates forming a new brood.

$r$ is calculated as follows:

$$
r=\frac{\sum_{j=1}^{n}\left(p_{j}^{\text {high }}-p_{j}^{\text {low }}\right)}{2 n} .
$$

7) it stop condition is verified the algorithm is finished otherwise go back to step 3.

The flow chart of SSO is shown in Figure 6.

\section{Simulation Results}

The SIMULINK model of Field Weakening Control for separately excited DC motor have been implemented using MATLAB/SIMULINK software as shown in Figure 7. The ratings and parameters of DC motor are shown in Table 1. PI controller in outer loop have been used to control the speed of the motor in both armature and field modes. To control the current of the motor, Hysteresis current method have been used in inner loop. The maximum current $\left(i_{a} \max \right)$ can the motor reach to it is twice the rated current. The voltage of field can be vraied by changing the duty ratio. For the speed equal or less than the rated speed the field current keep constant. For the speed higher than the rated speed the field current is varied to control the speed. Pre-data sets have been used as input and output to NN to training the weights and bais based on SSO. The training data are shown in Table 2. Each weights of the neural network will represent the male and female individuals. The number of individual is assumed to be 60 , while the range of parameters is supposed to be between $[0,1]$. The summation of the mean square error is taken as a fitness function. The structures of NN have three neorons in hidden layer and one neoron for the input layer and another one in the output layer. 


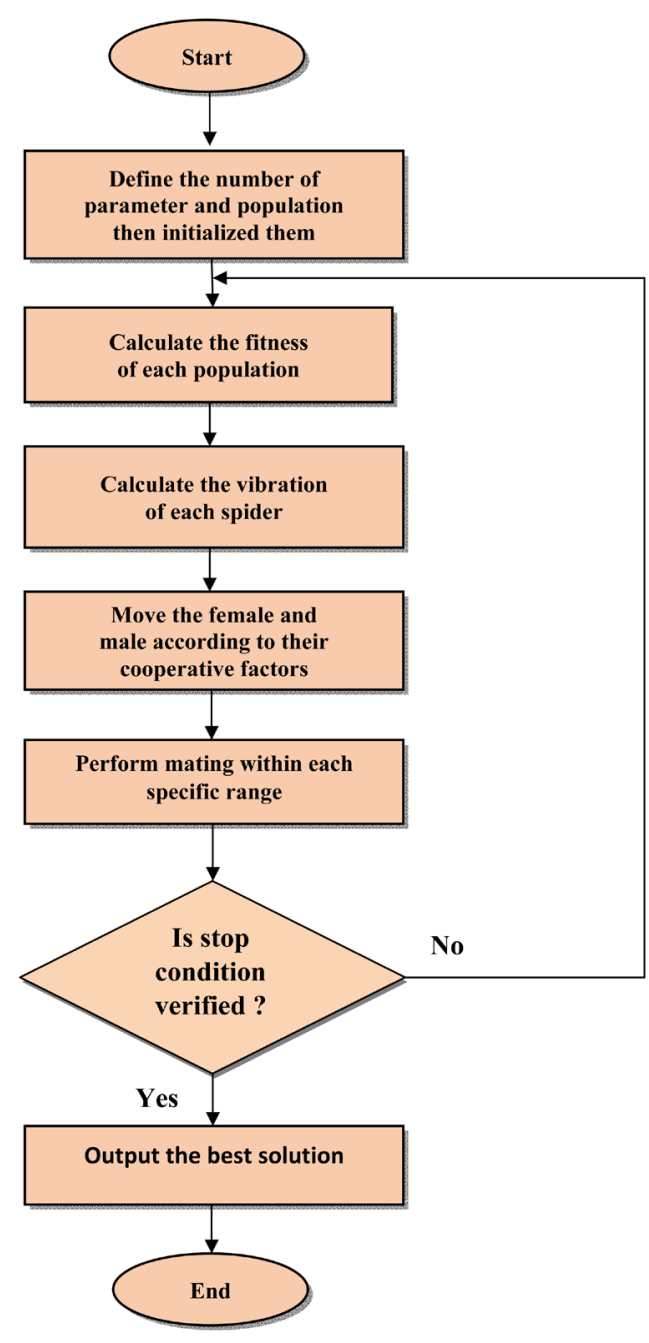

Figure 6. Flow chart of SSO.

Table 1. DC motor ratings and parameters.

$$
\begin{aligned}
\text { Nrated } & =1750 \mathrm{r} . \mathrm{pm} \\
v_{a} & =230 \mathrm{~V} \\
v_{f} & =120 \mathrm{~V} \\
i_{a} & =46 \mathrm{~A} \\
i_{f} & =1.6 \mathrm{~A} \\
L_{a f} & =0.767 \mathrm{H}
\end{aligned}
$$

$$
\begin{gathered}
L_{a}=0.008 \mathrm{H} \\
L_{f}=60 \mathrm{H} \\
R_{a}=0.1 \Omega \\
R_{f}=75 \Omega \\
B_{m}=0.314 \mathrm{Nm} \cdot \mathrm{S} / \mathrm{rad} \\
J=2.2 \mathrm{~kg} / \mathrm{m}^{2}
\end{gathered}
$$

The speed and field current responses of the motor under and over the rated speed is shown in Figure 8. The field current is $1.6 \mathrm{~A}$ for all speeds under rated speed of the motor which is 1750 r.p.m. A three step changes of 200 r.p.m in a reference speed is applied at $t=12,20$ and $28 \mathrm{~s}$ respectively. As shown in the responses (a) and (b), when the speed of the motor $\mathrm{N}$ increases over the rated speed $\mathrm{Nb}$ the field current decreases. Figure 9 show the summation of the mean square error to the number of training iterations. To drive the motor above rated speed by using field weakening method, the armature voltage should kept constant under the rated value. This can be clearly observed in Figure 10. Through step changes in the motor speed, the armature voltage will remaining almost constant below the rated voltage of the armature which equal to $225 \mathrm{v}$. 


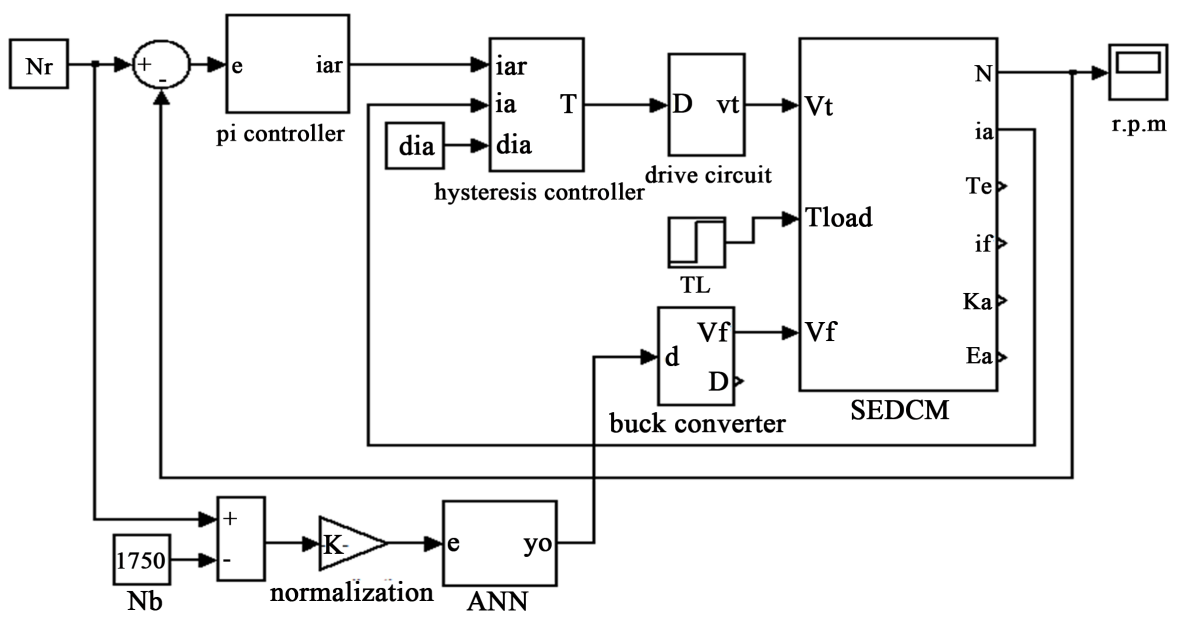

Figure 7. SIMULINK model of field weakening control for SEDCM.

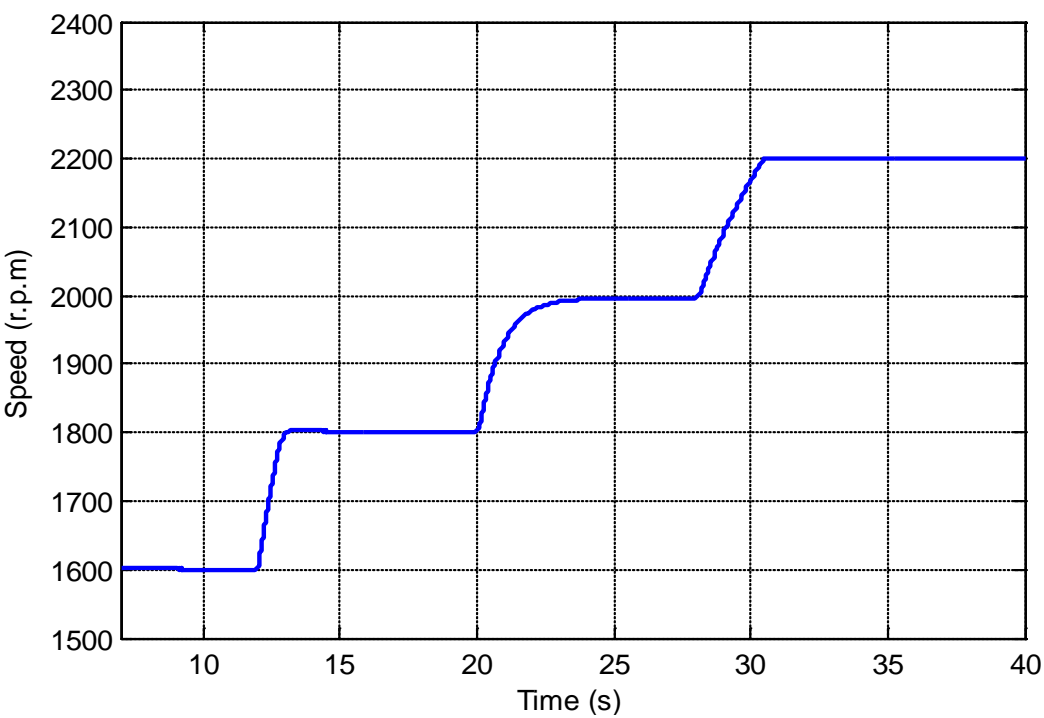

(a)

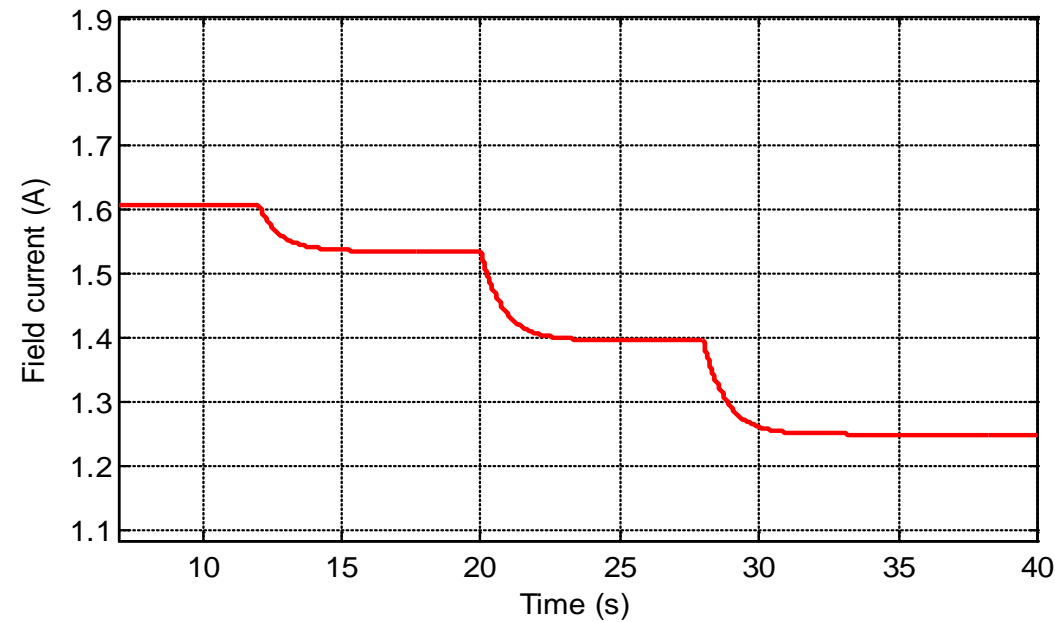

(b)

Figure 8. Speed and field current responses of the motor. 


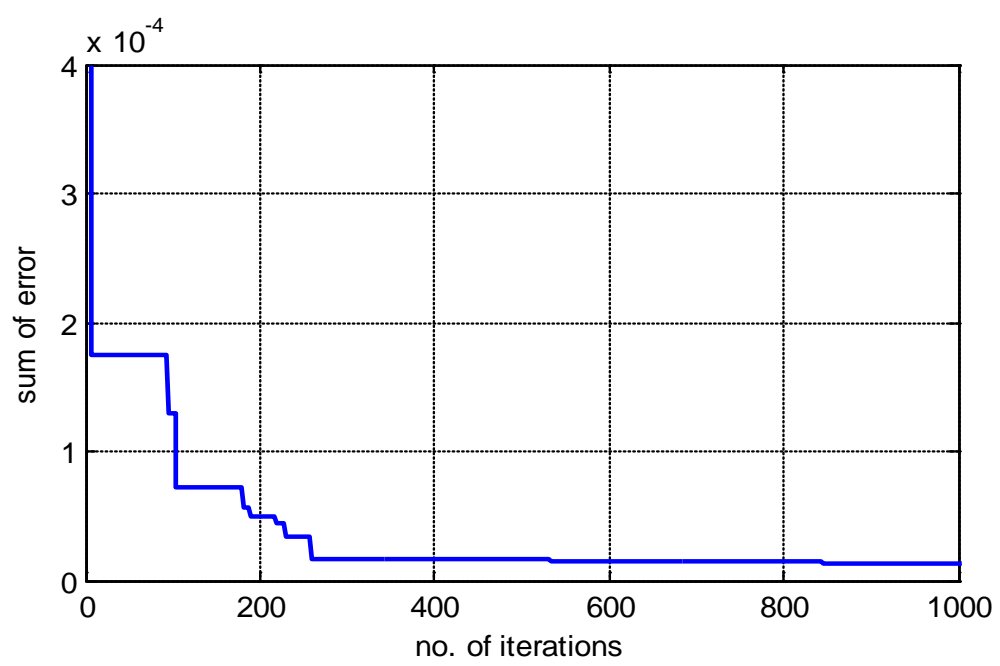

Figure 9. The summation of the mean square error.

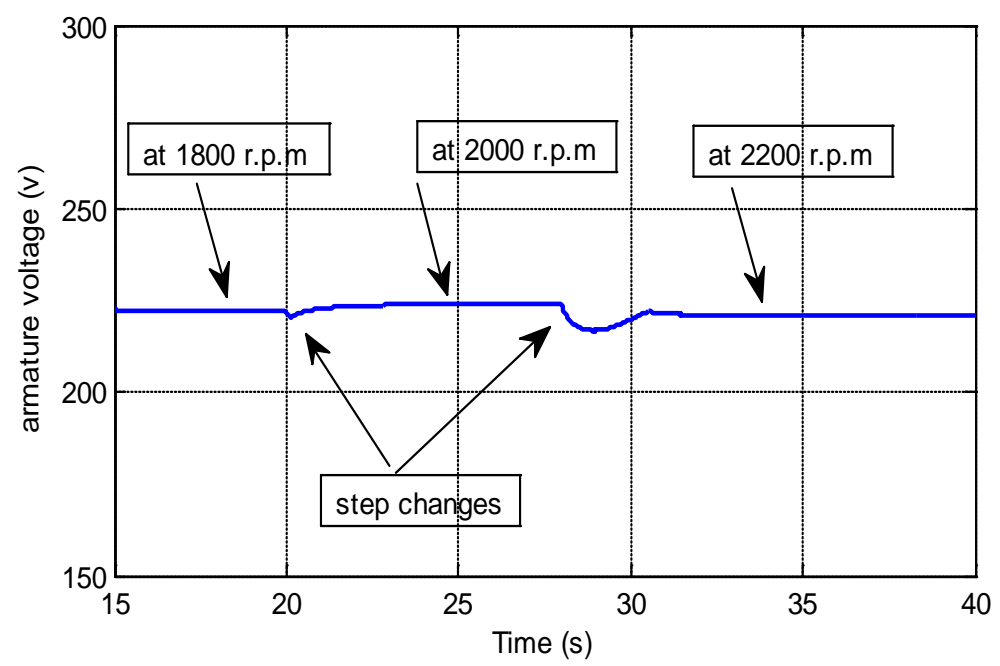

Figure 10. Armature voltage of the motor.

Table 2. Data sets for combined control.

\begin{tabular}{cccccccc}
\hline Data No. & $\begin{array}{c}\text { Normlized input } \\
(\mathrm{Nr}-\mathrm{Nb}) / \mathrm{Nb}\end{array}$ & $\begin{array}{c}\text { Requirement field } \\
\text { current (If) A }\end{array}$ & $\begin{array}{c}\text { Duty } \\
\text { ratio (D) }\end{array}$ & Data No. & $\begin{array}{c}\text { Normlized input } \\
(\mathrm{Nr}-\mathrm{Nb}) / \mathrm{Nb}\end{array}$ & $\begin{array}{c}\text { Requirement field } \\
\text { current (If) A }\end{array}$ & $\begin{array}{c}\text { Duty } \\
\text { ratio (D) }\end{array}$ \\
\hline 1 & -0.71 & 1.6 & 1 & 6 & 0.088 & 1.46 & 0.91 \\
2 & -0.428 & 1.6 & 1 & 7 & 0.137 & 1.4 & 0.87 \\
3 & -0.142 & 1.6 & 1 & 8 & 0.191 & 1.33 & 0.83 \\
4 & 0 & 1.6 & 1 & 9 & 0.25 & 1.26 & 0.78 \\
5 & 0.043 & 1.53 & 0.95 & 10 & 0.314 & 1.2 & 0.75 \\
\hline
\end{tabular}

\section{Conclusion}

The armature and field circuits of SEDCM are providing from separate sources; this can give a flexible control and wide speed rang. Field weakening methods are dependent on the reverse relationship between the field current and the speed of the motor. To control the speed of the motor from zero up to rated speed, armature control method is used and thus the motor drives in the constant torque region. While controlling the speed over the 
rated speed (the motor operates in the constant power region), field weakening methods should be used. In this work, the requirement field current has been predicted by using $\mathrm{NN}$ to drive the motor in both torque and power regions without needing any sensor to the armature voltage or field current. The parameters of NN optimized using SSO. The simulation results show the effectiveness of the proposed method.

\section{References}

[1] Tipsuwanpom, V., Numsomran, A., Klinsmitth, N. and Gulphanich, S. (2007) Separately Excited DC Motor Drive with Fuzzy Self-Organizing. International Conference on Control, Automation and Systems, Seoul.

[2] Zribi, M. and Al-Zamel, A. (2007) Field-Weakening Nonlinear Control of a Separately Excited DC Motor Mathematical Problems in Engineering. Hindawi Publishing Corporation.

[3] Liu, Z.Z., Luo, F.L. and Rashid, M.H. (2003) Speed Nonlinear Control of DC Motor Drive with Field Weakening. IEEE Transactions on Industry Applications, 39, 417-423. http://dx.doi.org/10.1109/TIA.2003.808971

[4] Adday, A.M. and Othman, M.Z. (2012) Combined Armature and Field Fuzzy Speed Control of a DC Motor for Efficiency Enhancement. Al-Rafidain Engineering, 20.

[5] Alshehhi, K.M.A.T. (2014) Combined Armature and Field Voltage Control of DC Motor. The British University in Dubai, December.

[6] Bose, B.K. (2006) Power Electronics and Motor Drives. Elsevier, USA.

[7] George, M., Basu, K.P. and Chiat, A.T.W. (2010) Model Reference Controlled Separately Excited DC Motor. Neural Computing and Applications, 19, 343-351. http://dx.doi.org/10.1007/s00521-009-0271-1

[8] Burns, R.S. (2001) Advanced Control Engineering. Butterworth-Heinemann, UK.

[9] Parpinelli, R.S. and Lopes, H.S. (2011) New Inspirations in Swarm Intelligence: A Survey. International Journal of Bio-Inspired Computation, 3, 1-16. http://dx.doi.org/10.1504/IJBIC.2011.038700

[10] Yim, M., Zhang, Y. and Duff, D. (2002) Modular Robots. IEEE Spectrum, 39, 30-34. http://dx.doi.org/10.1109/6.981854

[11] Cienfuegos, E., Zaldívar, M., Zaldívar, D. and Pérez-Cisneros, M. (2013) A Swarm Optimization Algorithm Inspired in the Behavior of the Social-Spider. Expert Systems with Applications, 40, 6374-6384. http://dx.doi.org/10.1016/j.eswa.2013.05.041

[12] Kennedy, J. and Eberhart, R. (1995) Particle Swarm Optimization. Proceedings of the 1995 IEEE International Conference on Neural Networks, 4, 1942-1948. http://dx.doi.org/10.1109/icnn.1995.488968

[13] Karaboga, D. (2005) An Idea Based on Honey Bee Swarm for Numerical Optimization. Technical Report-TR06, Engineering Faculty, Computer Engineering Department, Erciyes University.

[14] Yang, X.S. (2010) Engineering Optimization: An Introduction with Metaheuristic Applications. John Wiley \& Sons. http://dx.doi.org/10.1002/9780470640425

[15] Rajabioun, R. (2011) Cuckoo Optimization Algorithm. Applied Soft Computing, 11, 5508-5518. http://dx.doi.org/10.1016/j.asoc.2011.05.008 